\title{
Desenvolvimento de uma matriz de centralização para aumento de produtividade em uma empresa têxtil
}

\author{
Cassiano Rodrigues Moura \\ Instituto Federal de Santa Catarina (IFSC) \\ (cassianocrm@hotmail.com) \\ Elvis Círico \\ Instituto Federal de Santa Catarina (IFSC) \\ (elviss_c@hotmail.com)
}

\begin{abstract}
Resumo: É imprescindível, para o sucesso e a sobrevivência das organizações, a busca por uma melhora significativa no desempenho das empresas, tornando os equipamentos propícios a oferecer um aumento significativo de performance e, consequentemente, uma melhor produtividade. $\mathrm{O}$ objetivo geral deste trabalho é desenvolver um dispositivo para melhorar um sistema de manutenção autônoma e reduzir o tempo de espera dos equipamentos de costura, minimizando as perdas produtivas do processo de uma empresa têxtil. Esse dispositivo está sendo utilizado para troca rápida de matrizes em máquinas de costura do tipo filigrana e poderá ser manuseado pela própria área produtiva. O fluxo metodológico utilizado neste trabalho foi baseado em 3 (macro) atividades: a r̃definição da melhoriaò ñprojeto de melhoriaò e rãvaliação dos resultadosò Foi observado nos resultados uma melhora significativa nas condições gerais das matrizes utilizadas para aplicação de aviamentos em máquinas de filigrana que foram adaptadas para a melhoria, sendo que $51 \%$ foram alcançados em redução nos índices de ocorrências de manutenção e 33\% de redução no número de horas dedicadas ao dowtime.
\end{abstract}

Palavras-Chaves: Produtividade, Manutenção Autônoma, Indústria 4.0, Indústria Têxtil.

\section{Development of a centralization matrix for increased productivity in a textile company}

\begin{abstract}
It is essential for the success and survival of organizations to seek a significant improvement in the performance of companies, making the equipment propitious to offer a significant increase in performance and consequently better productivity. The general objective of this work is to develop a device to improve an autonomous maintenance system and reduce the waiting time of the sewing equipment, minimizing the productive losses of the process of a textile company. This device is being used for rapid exchange of matrices in sewing machines of the filigree type and can be handled by the productive area itself. The methodological flow used in this work was based on 3 (macro) activities, the "Definition of improvement"; "Improvement project" and "Evaluation of results". It was observed in the results that a significant improvement in the general conditions of the matrices used for application of fixtures in filigree machines were adapted for the improvement. As $51 \%$ were achieved in reduction in maintenance occurrence rates and $33 \%$ were achieved in reduction in the number of hours dedicated to downtime.
\end{abstract}

Keywords: Productivity, Autonomous Maintenance, Industry 4.0, Textile Industry.

\section{INTRODUÇÃO}

$\mathrm{Na}$ indústria têxtil, é válido destacar que o índice de confiabilidade dos equipamentos de costura pode diminuir caso a manutenção não seja tratada de 
acordo com a devida importância. Para isso, segundo Xenos (2004, p. 240), é necessário que os operadores tenham novas e desafiadoras responsabilidades onde participam da manutenção rotineira de seus equipamentos.

Hoje, na indústria da confecção têxtil, existe ainda uma restrição e uma distância entre o fato de operar a máquina e efetuar manutenções, ficando assim a produção totalmente dependente do manutentor. Isto faz com que ocorram paradas de máquinas e perda de produção devido ao fato de o equipamento perder rentabilidade produtiva ou até mesmo uma parada do mesmo devido a seus desgastes naturais das facas de corte, dispositivos móveis, entre outros, recorrentes da grande troca de modelos.

Diante disso, o objetivo deste trabalho é desenvolver um mecanismo que torne possível reduzir o tempo de espera dos equipamentos de costura têxtil, implantando um dispositivo de troca rápida, que poderá ser manuseado pela própria área produtiva. Para isso, busca-se envolver a equipe da área técnica no intuito de alinhar as informações e desenvolver uma solução de baixo custo que possa gerar retorno na minimização do tempo de espera dos equipamentos durante os setups visando assim melhorar os indicadores de desempenho da empresa viabilizar a redução da necessidade de intervenção mecânica disponibilizando a área técnica para outras necessidades de mão de obra especializada.

Por fim, este trabalho busca destacar e desenvolver uma alternativa aplicável, onde a própria produção possa contribuir a manter o perfeito funcionamento dos equipamentos, evitando a parada e/ou diminuição da capacidade produtiva de um equipamento.

\section{REFERENCIAL BIBLIOGRÁFICO}

\subsection{Caracterização do setor têxtil}

A Associação Brasileira da Indústria Têxtil e de Confecção (ABIT) é uma das mais importantes entidades dentre os setores econômicos do País, foi fundada em 1957. Ela representa a força produtiva das empresas do setor têxtil instalada por todo o território nacional. Conforme ABIT (2017), a indústria têxtil com um faturamento crescente que fechou em US\$ 45 bilhões em 2017 é o setor 
responsável por uma série de resultados consideráveis para o país, sendo também o segundo maior gerador de primeiro emprego. Tem mais de 29 mil empresas formais em todo o país, é o quarto maior parque produtivo de confecção do mundo e o quinto maior produtor têxtil do mundo além de ser responsável por empregar cerca de 1,479 milhão de empregados diretos e 8 milhões de indiretos onde $75 \%$ são mãos de obra feminina. É o segundo maior empregador da indústria de transformação, perdendo apenas para alimentos e bebidas juntos.

No Brasil, o setor têxtil é responsável pela quarta maior cadeia produtiva integrada e verticalizada do mundo, sendo a maior do Ocidente. A indústria têxtil e de confecção nacional é uma das poucas existentes que se inicia na produção ou cultivo das fibras, que se transformam em não tecidos ou passam pela construção do fio, seguido da fabricação do tecido ou da malha (ABIT, 2017).

A indústria têxtil e do vestuário encontra-se em época de grandes mudanças, o mundo em que vivemos, fortemente marcado pela revolução das comunicações das últimas décadas mudou substancialmente e exige uma formação profissional em sintonia com a nova ordem internacional, que vem se desenvolvendo de uma forma muito dinâmica (MELO, 2007).

Com o mercado têxtil cada vez mais exigente, tanto quanto as inovações tecnológicas, novidades em r̃̃lesignò modernização dos parques fabris, ainda são imprescindíveis à competitividade na questão de custos, que são todos os fatores importantes na diferenciação de produtos para a conquista de mercados. Outro fator decisivo para a diferenciação e competitividade no setor têxtil é o desenvolvimento rápido de uma coleção, baseado em uma tendência do mercado da moda. Araújo (1996) apresenta um Sistema de Resposta Rápida, que se baseia na produção rápida e flexível.

Neste sistema, o prazo da entrega da encomenda fica estipulado em um ideal básico de quatro semanas, onde: duas semanas, formula-se o design da coleção; uma semana: fabricação do tecido; uma semana: confecção das peças. Existe uma flexibilidade inerente que permite a colocação de mais encomendas de menor volume, que é uma característica cada vez mais presente e exigida das empresas no ramo têxtil. O tempo de produção das peças se torna então uma questão de sobrevivência para as organizações. O sucesso das empresas de confecção e vestuário depende da forma como se posicionam perante a concorrência em função de fatores determinantes da competitividade. 
Conforme descrito por Melo (2007), para que o setor seja mais competitivo e produtivo, em um mercado cada vez mais globalizado, são necessários investimentos maciços em máquinas e equipamentos, para compensar uma defasagem tecnológica que impede o avanço da competitividade da indústria têxtil no mercado externo. Pensando em novos métodos de gestão e em novas tecnologias, a orientação só pode ser uma, o investimento em modernização. Um dos possíveis caminhos a seguir é a utilização crescente de sistemas de produção flexíveis para responder rapidamente a segmentos do mercado onde o valor acrescentado é elevado. Desta forma, é válido ressaltar que o investimento em melhorias nos equipamentos a fim de reduzir o tempo de produção por peça é mais um passo para tornar a organização mais eficiente e condizente com a atual realidade das indústrias (ARAÚJO, 1996).

Para aumentar sua produtividade e faturamento, as corporações necessitam substituir técnicas utilizadas habitualmente, pois a atitude de se contentar com formas antigas de produzir as impedem de se desenvolver, essas organizações tendem buscar alternativas para substituir as utilizadas atualmente (NELSON e WINTER, 2005). O processo de inovação no setor de vestuário é complexo, um dos desafios para se inovar é dar atenção às demandas dos consumidores, que se tornam cada vez mais exigentes em relação a aspectos como ambientais, segurança, ergonomia e preço. Em contrapartida, as empresas lidam com limitações no orçamento, tecnologia, registro de patente, incertezas e riscos ao investir em inovação. Como consequência, torna-se cada vez mais difícil oferecer produtos competitivos no mercado (COSTA, 2011).

Do ponto de vista do autor Araújo (1996), a automatização tradicional é caracterizada por ser pouco flexível, só se justificando para produções em grande escala, contudo, já é possível encontrar máquinas de costura com automatizações que são voltadas à execução repetitiva de uma ou mais operações de costura. A automação na costura possui suas limitações por ser complexa, sobretudo devido ao fato do produto a ser produzido ser geralmente muito flexível, de dimensões variáveis e de dimensões variáveis (sobretudo as malhas). O ciclo de trabalho consiste em pegar as partes de uma peça, juntá-las, guiá-las na costura e retirá-las da máquina. A automatização destas operações é complexa. O problema se agrava quando se torna necessário alterar material e/ou modelagem das peças a se costurar (ARAÚJO, 1996). 
As empresas do setor têxtil e de confecção estão em busca de melhoria, através de inovações e não apenas uma melhoria focada simplesmente na questão econômica e financeira das mesmas. Elas almejam um processo mais rico, que possa promover mudanças que agreguem valor, o que significa, em última análise, nos darmos conta das implicações humanas quando da adoção de técnicas de gerenciamento (ABRANCHES e SILVA, 1995).

\subsection{A indústria 4.0}

O termo Indústria 4.0 (Industrie 4.0) foi primeiramente utilizado em um relatório do grupo de trabalho para o desenvolvimento da manufatura para o governo da Alemanha. Este grupo de trabalho se originou de uma associação de representantes do governo, onde empresas e academia promoveram a ideia de uma abordagem a fim de aprimorar a competitividade da indústria alemã. O governo alemão, após apoiar a iniciativa, anunciou que esta quarta revolução industrial seria então denominada como indústria 4.0 e seria parte de seu projeto High-Tech Strategy 2020 for Germany, com o propósito de levar a Alemanha à liderança na inovação tecnológica. Esta nova revolução proporciona uma nova era da indústria, centralizada na utilização de recursos de informação e tecnologia da comunicação (ICT) para que assim, seja possível melhorar o processo de manufatura e negócio (KAGERMANN et al., 2013).

Entre os princípios para o desenvolvimento e implantação da indústria 4.0, que definem os sistemas de produção inteligentes que tendem a surgir nos próximos anos, está a modularidade, que é a produção de acordo com a demanda, acoplamento e desacoplamento de módulos na produção, o que oferece flexibilidade para alterar as tarefas das máquinas facilmente (SILVEIRA, 2018).

Outro princípio na criação da indústria 4.0 é o surgimento do que tem sido chamado de smart factory, que é um fábrica inteligente com estrutura modular, em que os sistemas ciberfísicos monitoram processos físicos ï criando uma cópia virtual do mundo físico e tomam decisões descentralizadas; fazem uso intenso de sistemas ciberfísicos e internet das coisas, que se comunica entre si e com humanos em tempo real. Esta nova cadeia viabiliza o desenvolvimento de novos modelos de negócios com diferentes organizações do trabalho. Estas possibilidades de arranjo 
das diferentes alternativas das tecnologias da Indústria 4.0 podem resultar em diversos benefícios (KAGERMANN et al., 2013).

Schwab (2017) também ressalta que a tecnologia tornou possíveis novos produtos e serviços que aumentam a eficiência e o prazer de nossas vidas pessoais. Pedir um táxi, reservar um voo, comprar um produto, fazer um pagamento, ouvir música, assistir a um filme ou jogar um jogo, qualquer um deles agora pode ser feito remotamente.

Esta revolução tecnológica que estamos vivendo alterará fundamentalmente a maneira como vivemos, trabalhamos e nos relacionamos uns com os outros. Em sua escala, escopo e complexidade, a transformação será diferente de tudo o que a humanidade já experimentou antes. Ainda não sabemos exatamente como isso vai se desdobrar, mas uma coisa é clara: a resposta a ela deve ser integrada e abrangente, envolvendo todos os atores da comunidade global, dos setores público e privado à academia e à sociedade civil (OLIVEIRA, 2018).

Conforme Bouças (2018), o país é atualmente o quinto maior produtor têxtil do mundo, atrás de China e Índia, Estados Unidos e Paquistão. Em confecção, é o quarto maior produtor global, atrás de China, Índia e Paquistão. De acordo com o estudo, o Brasil está alinhado com outros grandes produtores têxteis e vestuário no mundo no que se refere à automação industrial e à implantação da chamada indústria 4.0, que inclui também, além da automação, o uso da internet das coisas para conectar máquinas e equipamentos entre si para garantir uma produção mais ágil e com menos perdas.

\section{METODOLOGIA}

Neste trabalho, o levantamento dos dados conceitualmente foi realizado utilizando o tipo de pesquisa exploratória, objetivando oferecer uma visão panorâmica da situação prática a ser explorada. Pode-se dizer também que esta pesquisa é denominada como ñpesquisa de baseò como cita a autora Gonsalves (2011), pois oferece dados elementares que servirão de suporte para a realização de estudos mais aprofundados sobre o tema proposto.

Procurou-se desenvolver uma forma de reduzir consideravelmente os índices de downtime dos equipamentos, ocasionados por setups no setor da costura. $O$ 
objetivo foi identificar, dentre os maiores índices de setups na fábrica, um item que se apresenta viável para desenvolver uma melhoria eficaz e definitiva, atendendo questões de produtividade como o custo benefício. O fluxo metodológico utilizado neste trabalho é apresentado na Figura 1, onde pode-se observar 3 (macro) atividades, a ñDefinição de melhoriaò r̃ Projeto de melhoriaò e ñavaliação dos resultadosò

Figura 1: Fluxo metodológico adotado neste trabalho

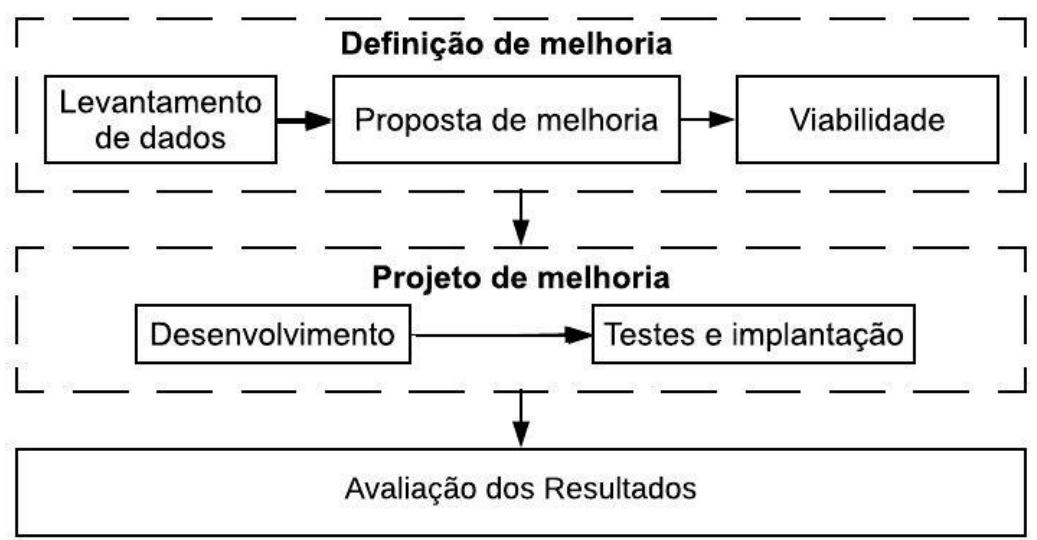

Fonte: Autores

\section{DESENVOLVIMENTO}

\subsection{Levantamento de dados}

Através da coleta das informações geradas pelo sistema SAP utilizado na empresa, pode-se trabalhar com os dados de forma organizada, tornando possível dispor estas informações e detalhar todas as interferências manutentivas nos equipamentos do setor da costura. Nesse relatório, é possível identificar as causas das ocorrências, bem como filtrá-las por quebra, manutenção programada ou setup, que é o foco utilizado neste trabalho.

Este relatório, apresentado na Tabela 1, é alimentado pelos próprios operadores, que, através de uma transação específica do SAP, registram a necessidade de uma intervenção mecânica de acordo com a dificuldade encontrada, gerando assim uma nota de manutenção que é transformada em ordem pelo próprio manutentor no momento do atendimento à ocorrência. Nesta nota, o operador da produção registra o número do equipamento em questão e na descrição o mesmo insere manualmente informações sobre a necessidade daquele chamado. 
O campo com a denominação do equipamento é preenchido automaticamente através do número do equipamento inserido pelo operador, que, através deste número, o sistema informa (preenche) o campo ñDenominaçãoò conhecido internamente como operação, ou seja, o que o equipamento é desenvolvido ou adaptado para costurar, basicamente, operação é o acabamento que o equipamento é projetado/preparado para realizar na peça que será costurada. O manutentor, após o seu atendimento à ocorrência, fecha a ordem, inserindo o que foi ajustado no equipamento, e os devidos tempos utilizados, alimentando assim os dados necessários para que seja gerado o ñTempo de duração da paradaò é o que conhecemos internamente como downtime. Este demonstra o tempo real que o equipamento ficou sem produzir devido ao problema ou ajuste necessário, conforme pode-se verificar na Tabela 1.

Tabela 1: Visão parcial do relatório gerado no sistema SAP das notas de manutenção.

\begin{tabular}{cccc}
\hline Equipamento & Denominação & Descrição & $\begin{array}{c}\text { Duração } \\
\text { Parada (min) }\end{array}$ \\
\hline 2005335 & o conjugado c/transporte superior & patina & 22 \\
\hline 2007137 & costura reta & quebra agulha & 75 \\
\hline 2000503 & abrir bolso coração & não corta tecido & 17 \\
\hline 2000742 & pregar bolso & arrebenta linha & 12 \\
\hline 2000566 & pregar gola com tira & patina na entrada & 73 \\
\hline 2006612 & pregar bolso & não dobra bolso & 25 \\
\hline 2004712 & crbr & vaza ar & 17 \\
\hline 2003107 & botão manual & regular programa & 12 \\
\hline 2000211 & pregar bolso & centralizar marratriz o7 & 50 \\
\hline 2001789 & pregar bolso embutido automático & regular laser & 78 \\
\hline 2003444 & costura reta & regular franzido & 67 \\
\hline 2000613 & costura reta & embuchando & 17 \\
\hline 2002146 & pregar passante & regular pinça & 85 \\
\hline 2009176 & caseado olho & faca do caseado & 17 \\
\hline 2007131 & costura reta & não corta & 50 \\
\hline 2001789 & pregar bolso embutido automático & regular franzido & abre arremate \\
\hline 2007548 & pregar bolso & programa 3401 não & 25 \\
\hline 2000636 & o conjugado & está na memoria & 58 \\
\hline 2000284 & pregar gola com tira & sobe resíduo & 17 \\
\hline 2003294 & gov com alp & variação no punho & 40 \\
\hline 2000075 & pregar gola com tira & patina na entrada & 07 \\
\hline 2001317 & o pico & regular pra modelo & 75 \\
\hline 2007027 & filigrana lapela & verificar velocidade & 00 \\
\hline 2007748 & embutidor & empurra & 17 \\
\hline
\end{tabular}


Com base nestas informações, foi possível identificar, entre todas as ocorrências, as 10 principais, ou seja, as que causam maior impacto na parada dos equipamentos, sendo as que geram maior downtime (tempo de parada do equipamento). Na Figura 2 é apresentada a representação das ocorrências de setup no período de janeiro a setembro do ano 2018, momento em que foram compiladas as informações para esta pesquisa. É possível visualizar que, neste ano, o item ĩPrograma descentralizadoò que é o foco deste trabalho, está ocupando o primeiro lugar em downtime, com quase 400 minutos. Este índice corresponde a 66\% do total destas ocorrências no ano de 2017 e já é um acréscimo considerável na quantidade de ocorrências visualizadas no ano de 2016, ressaltando ainda mais a importância de sanar este índice, que se mantém entre as principais ocorrências dos últimos levantamentos.

Figura 2: Principais ocorrências de setup (2018)

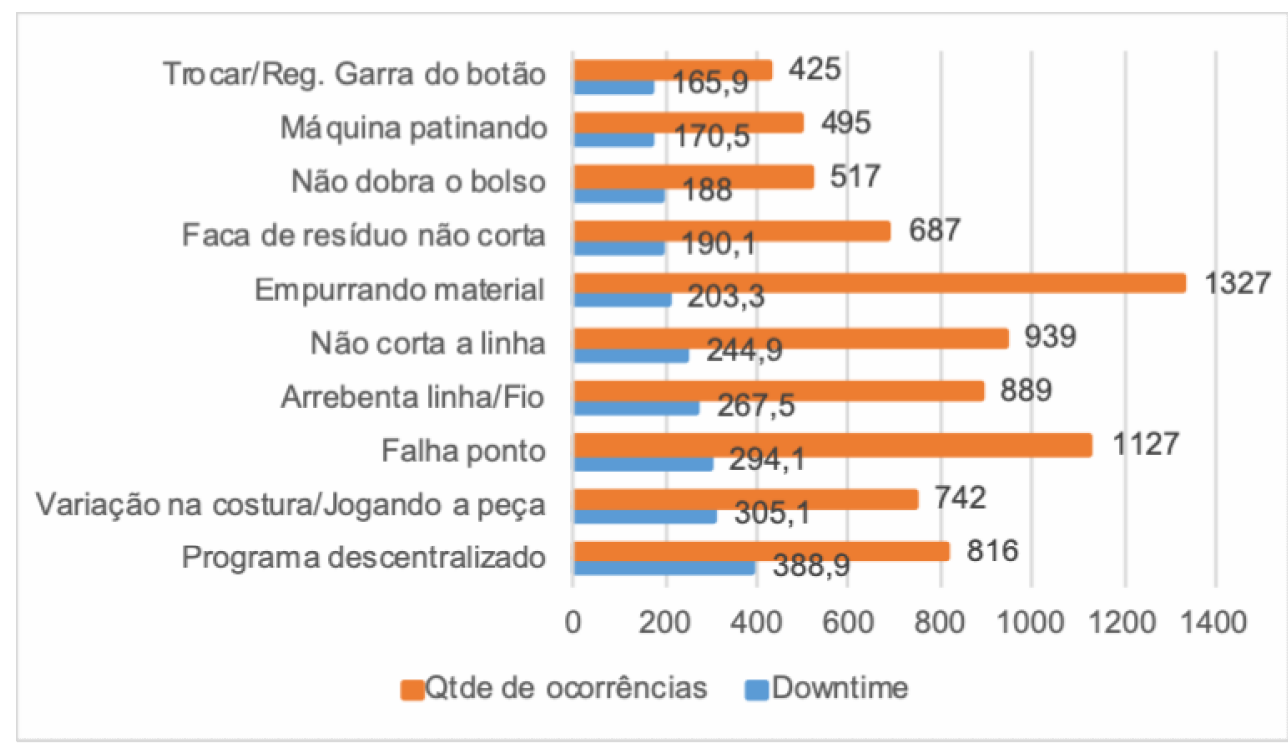

Fonte: Autores

Na Tabela 2 é possível observar uma lista contendo algumas ocorrências do ano de 2018, bem como seu grau de importância e as tratativas e/ou sugestões de melhoria para algumas delas. Este alinhamento é necessário para que seja devidamente disposta a oportunidade de todos se pronunciarem e apresentarem suas sugestões de melhorias. Estas sugestões podem ser de alterações no próprio equipamento, desde pequenos guias até a criação de automações, por exemplo, assim como também pode ser uma simples alteração do processo ou método de trabalho. 
Tabela 2: Tratativas das melhorias conforme ocorrências (2018).

\begin{tabular}{ccc}
\hline Ocorrência & Importância & Tratativa / Sugestão \\
\hline Programa descentralizado & 1 & Em andamento / pinagem de matrizes \\
\hline $\begin{array}{c}\text { Variação na costura/Jogando } \\
\text { a peça }\end{array}$ & 2 & \\
\hline Falha o ponto & 3 & Alterado fornecedor de linhas \\
\hline Arrebenta linha ou fio & 4 & Alterado fornecedor de linhas \\
\hline Não corta a linha & 5 & \\
\hline Empurrando o material & 6 & Adaptado máquina com transporte auxiliar \\
\hline Faca de resíduo não corta & 7 & - \\
\hline Não dobra o bolso & 8 & - \\
\hline Máquina patinando & 9 & - \\
\hline Trocar/Reg. garra do botão & 10 &
\end{tabular}

\subsection{Proposta de melhoria}

Neste trabalho é apresentada uma proposta de melhoria piloto para a principal problemática do ano de 2018, que é o r̃Programa descentralizadoò Este também se repetiu nos anos anteriores de 2016 e 2017, porém com menor ênfase, mas ainda assim esteve entre as principais ocorrências anuais, onde só neste ano gerou paradas na ordem de $400 \mathrm{~min}$. Assim, a proposta de melhoria apresentada consiste em desenvolver um sistema de fixação através de dois pinos na parte superior, onde a matriz é fixada no equipamento, que atualmente não possui nenhum dispositivo de fixação. Esta matriz pode ser observada na Figura 2.

Devido ao fato de não haver nada que fixe o posicionamento desta, podem acontecer diversos erros de posicionamento a cada troca realizada. Com a inserção desta melhoria, espera-se também que seja eliminada a necessidade de mecânicos efetuarem a centralização de matrizes nos equipamentos filigrana da marca Brohter modelo BAS 326G. Normalmente este equipamento é utilizado para a costura de etiquetas, apliques, plaquetas e demais aviamentos utilizados na indústria do vestuário. 
Figura 2: Melhoria da matriz para aplicação de plaquetas.

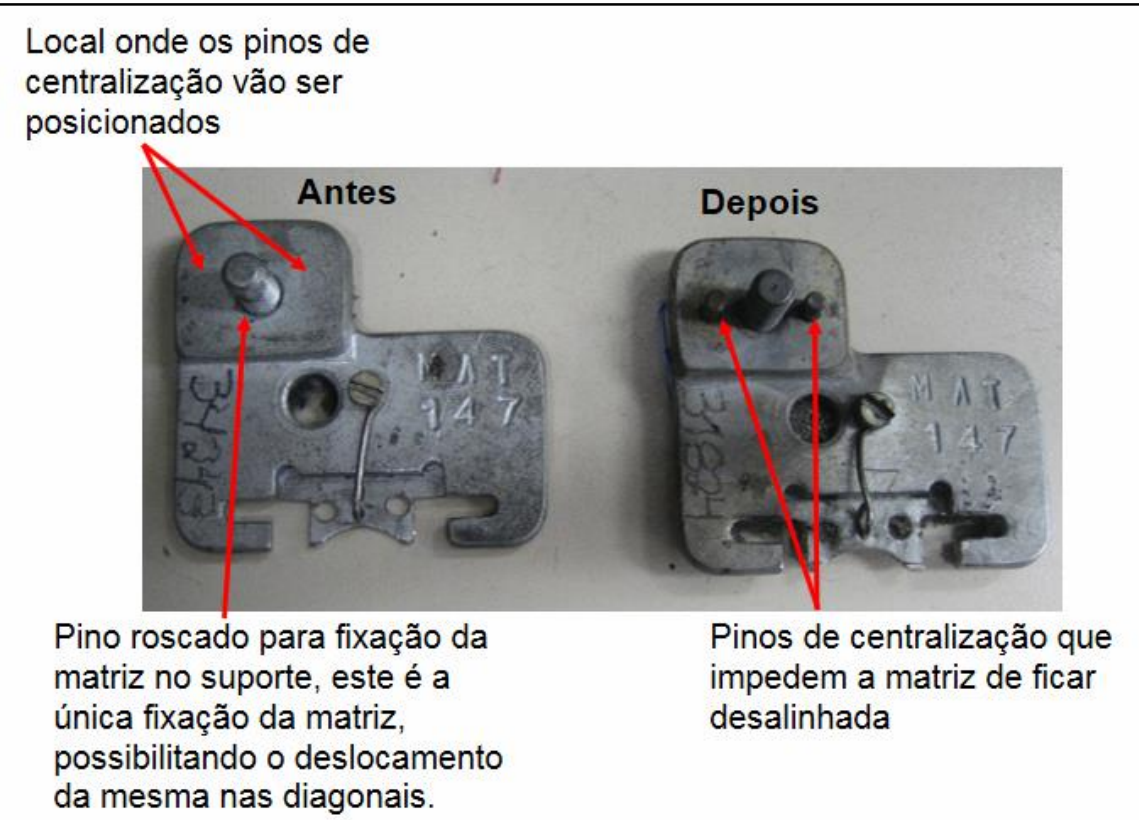

Fonte: Autores

\subsection{Estudo de viabilidade}

O estudo de viabilidade é necessário, além de outros fatores, para que seja verificado o payback, que é o tempo que a alteração/melhoria possui para gerar retorno, ou seja, trata-se de uma estratégia, um indicador usado nas empresas para calcular o período de retorno de investimento em um projeto. Com o custo da melhoria definido, avalia-se da mesma forma as ocorrências manutentivas evitadas, assim, sabe-se a viabilidade de realizar ou não a melhoria proposta. A política da empresa para tomada de decisão em paybackës é positiva quando a melhoria implantada gera o retorno investido o mais breve possível, levando em consideração a seguinte estratégia:

- melhorias que se pagam em até 6 meses: podem ser implantadas de imediato;

- melhorias que se pagam em até 1 ano: devem ser programadas e implantadas gradativamente, evitando-se que o custo seja gerado de uma única vez para a empresa; 
- melhorias que se pagam entre 1,5 e 2 anos devem ser bem avaliadas juntamente com o gestor da área produtiva e manutentivas para decisão em conjunto;

- melhorias que se pagam acima de 2 anos: são declaradas inviáveis de imediato.

O custo deste desenvolvimento deverá ser rateado pela quantidade total de máquinas filigrana Brother disponíveis, que são 50 máquinas distribuídas por todo o setor fabril da empresa matriz, isto sem levar em consideração as filiais, onde os trabalhos poderão ser replicados posteriormente. A Tabela 3 apresenta a discriminação dos valores referentes ao custo de implantação da melhoria.

Tabela 3: Cálculo do custo estimado para implantação da melhoria por equipamento

\begin{tabular}{|c|c|c|c|}
\hline Descrição custo & Rateio & Custo total & $\begin{array}{l}\text { Custo } \\
\text { final }\end{array}$ \\
\hline Matriz de centralização & Sim & $\mathrm{R} \$ 227,00$ & $\mathrm{R} \$ 4,54$ \\
\hline Custo aproximado de pinagem de uma matriz usada & Sim & $\mathrm{R} \$ 50,00$ & $\mathrm{R} \$ 1,00$ \\
\hline Custo fabricação matriz nova & Sim & $\mathrm{R} \$ 113,00$ & $\mathrm{R} \$ 2,26$ \\
\hline Mão de obra para furação dos suportes & Não & $\mathrm{R} \$ 14,00$ & $\mathrm{R} \$ 14,00$ \\
\hline \multirow{2}{*}{$\begin{array}{l}\text { Custo estipulado com a mão de obra para ajuste de uma } \\
\text { máquina com a matriz de centralização e os programas de } \\
\text { todas as matrizes }\end{array}$} & Não & $\mathrm{R} \$ 114,00$ & $\mathrm{R} \$ 114,00$ \\
\hline & $\begin{array}{l}\text { Custo } \\
\text { por equ }\end{array}$ & $\begin{array}{l}\text { aproximado } \\
\text { dipamento: }\end{array}$ & $R \$ 135,80$ \\
\hline
\end{tabular}

Fonte: Autores

Aproximadamente $84 \%$ do custo de implantação desta melhoria consiste na utilização da mão de obra. Isto se deve ao fato da necessidade dos ajustes que necessitam ser realizados em todos os equipamentos que irão receber esta adequação.

\subsection{Projeto de melhoria}

Neste projeto, a matriz de centralização foi idealizada pelos próprios manutentores e projetada pelo setor de ferramentaria. O projeto, bem como suas dimensões, podem ser visualizados na Figura 3. Esta matriz foi produzida em aço 1020, já as buchas onde passam os pinos de centralização serão fabricadas em aço prata, com tratamento para dureza de $55 \mathrm{HRc}$, devido a sua maior resistência. Já os próprios pinos de centralização também utilizarão o aço prata para sua fabricação, 
porém recebem tratamento térmico para atingirem em torno de $35 \mathrm{HRc}$. Os materiais utilizados na fabricação deste conjunto de centralização foram materiais reaproveitados (refugos) que seriam descartados, não gerando custo com os mesmos, somente com a mão de obra de fabricação.

Figura 3: Projeto matriz de centralização; (a) Vista frontal; (b) Vista superior; (c) Vista isométrica.

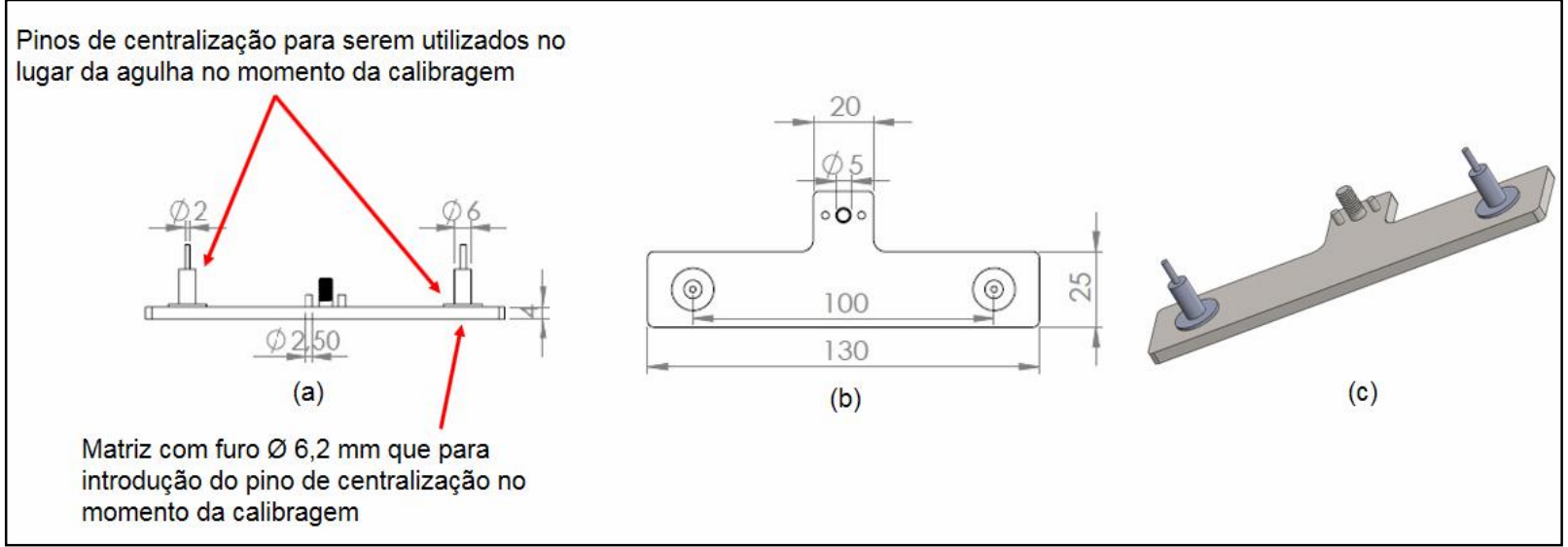

Fonte: Autores

A matriz de centralização, juntamente com os pinos de centralização, foi denominada kit de centralização, que pode ser observado na Figura 4(a). Ele é composto pela matriz de posicionamento (ver Figura 4b) e um pino de centralização (ver Figura 4c), este pino é fixado no lugar da agulha, para então ajustar um ponto zero padrão para todos os equipamentos.

Figura 4: Dispositivos desenvolvidos para centralização; (a) Kit de centralização; (b) matriz de posicionamento; (c) pino de centralização.

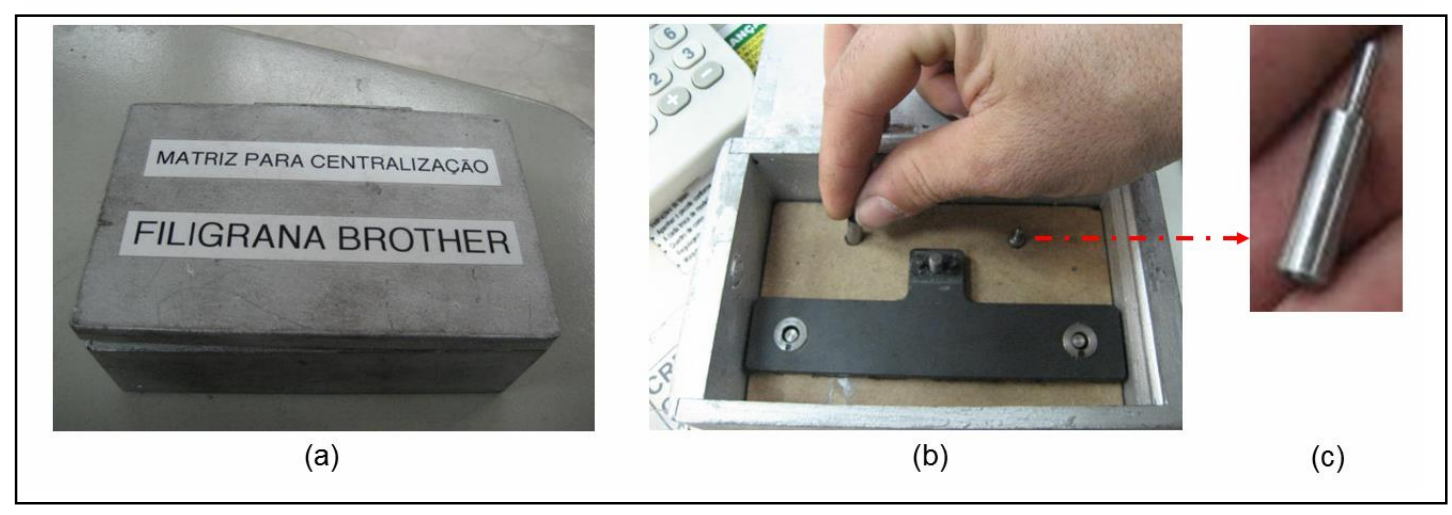

Fonte: Autores 
Para a utilização deste sistema, foi necessário realizar uma furação no suporte de fixação das matrizes, conforme se pode observar na Figura 5 (a). Este procedimento foi necessário para que todo o sistema trabalhe ancorado pela pinagem, garantindo o mesmo posicionamento tanto na posição $X$ como na posição $Y$ para todas as matrizes que venham a ser utilizadas neste equipamento. Desta forma, todas as matrizes devem possuir dois pinos nas extremidades de seus suportes, conforme mostra a Figura 5 (b), estes são utilizados como posicionadores e impedem que qualquer matriz utilizada seja posicionada de forma incorreta.

A própria matriz de centralização já vem com os referidos pinos, de forma a servir como padrão para o ajuste do equipamento, conforme é apresentado também na Figura 5 (b). O pino de centralização utilizado para referência com a matriz é fixado no suporte de agulha e fixo com o mesmo parafuso da agulha, conforme possível visualizar na Figura 5 (c), onde está sendo realizada a fixação do mesmo, com o auxílio de uma chave de fenda.

Figura 5: Método de utilização do Kit de centralização; (a) Furação no suporte de fixação;

(b) Pinos de centralização; (c) Fixação do suporte.

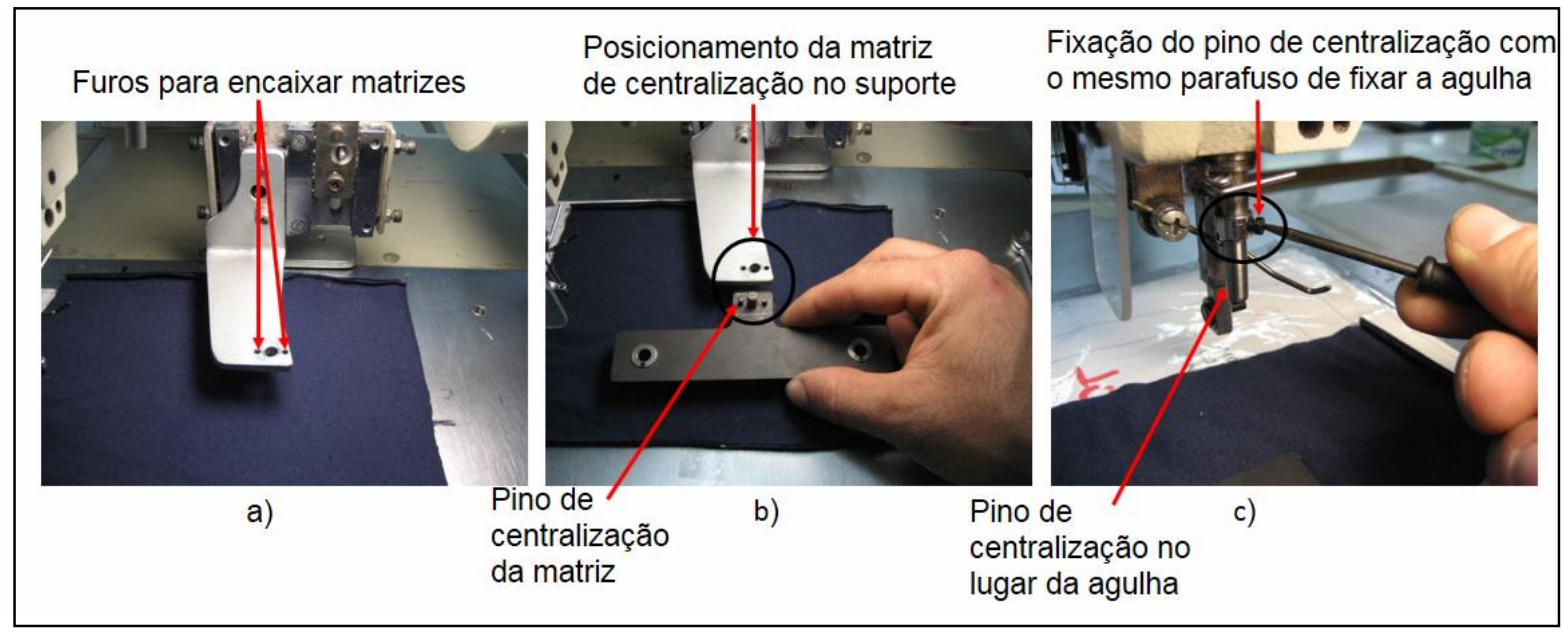

Fonte: Autores

\subsection{Implantação e avaliação de resultados}

Os testes, após o desenvolvimento da matriz de centralização, foram realizados no setor responsável pela produção das peças piloto, ou seja, assim que um modelo é criado pelo setor de estilo, ele é modelado, cortado e costurado para verificação dos possíveis problemas que possam ocorrer, bem como para 
visualização da peça pronta, que muitas vezes pode ainda vir a receber algum tipo de alteração.

Nesta fase ocorreu a padronização do processo, de forma a garantir que o procedimento seja executado por qualquer manutentor e tenha o mesmo resultado final de centralização. Deve-se garantir que todos os equipamentos estejam com o mesmo ponto zero, que é posicionamento dos eixos $X$ e $Y$ de forma idêntica. Para isso, foi criado internamente um documento norteador, com instruções passo a passo para a utilização da matriz de centralização.

Após os primeiros meses corridos, foi possível reformular os gráficos de acompanhamento e levantamento de dados apresentados neste trabalho para fins de comparação da implantação do projeto, conforme mostra a Figura 6, onde podese observar uma redução nos índices de ocorrências de manutenção, que diminuiu de 1630 para 800 ocorrências em 2018, representado uma melhoria de 51\%. Com relação às horas dedicadas ao dowtime, pode-se observar uma redução de 33\% no número de horas com relação ao período de 2017, isto é resultado das paradas para implantação das melhorias alinhado ao treinamento dos operadores.

Figura 6: Quantidade de ocorrências x downtime por centralização de programas/matrizes.

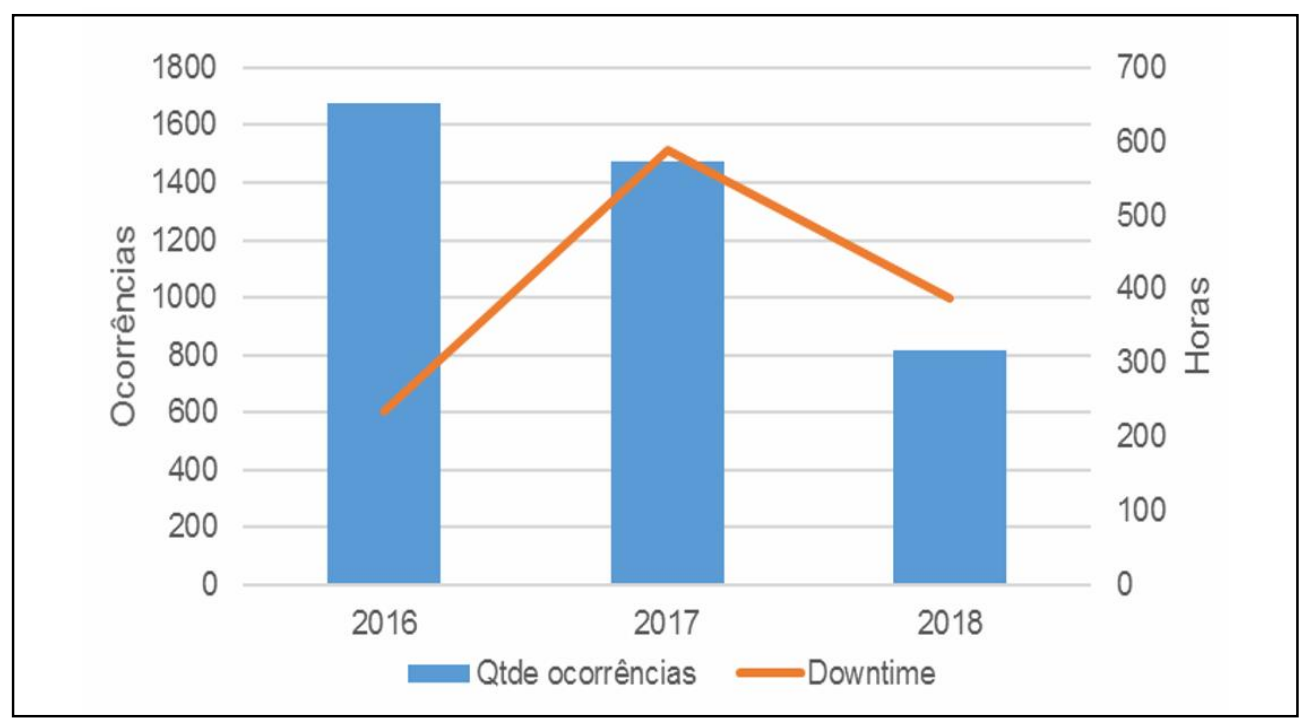

Fonte: Autores 


\section{CONSIDERAÇÕES FINAIS}

Com a padronização realizada nos equipamentos, bem como com a intercambiabilidade de matrizes entre os mesmos, atende-se também a um dos critérios que liga esta melhoria ao desenvolvimento e aplicação da indústria 4.0, que é a modularidade, ou seja, é a produção de acordo com a demanda, o acoplamento e desacoplamento de módulos na produção. Isso oferece flexibilidade para alterar as tarefas das máquinas facilmente, atendendo assim a nova demanda da indústria têxtil, que, conforme Araújo (1996), as organizações têm que lidar cada vez mais com coleções de vida curta, entregas rápidas, pequenas séries de peças, construções complicadas, fluxo de trabalhos complexos e maiores exigências. Assim, como cita o autor Kagermann et al., (2013), o princípio para a criação da fábrica inteligente (smart factory) está na fábrica possuir estrutura modular, começando pelos equipamentos.

Pode-se observar que, através dos levantamentos de dados realizados, onde foram identificadas as principais ocorrências que mais ofereciam impacto na produtividade em termos de setup, foi possível consultar junto aos manutentores quais ações poderiam ser implantadas para que os próprios operadores realizassem os setups em seus equipamentos, sem a necessidade de intervenção mecânica, que ofereça facilidade de implantação, menor custo e ofereça menor impacto nas atividades dos operadores.

Desta forma, com o desenvolvimento da melhoria, a simples tarefa de trocar de modelo a ser produzido pode ser realizada integralmente pelo operador, não sendo necessária nenhum tipo de intervenção mecânica para este fim, viabilizando ao setor produtivo efetuar trocas rápidas de dispositivos, otimizando a utilização dos equipamentos e gerando aumento de produtividade, onde, consequentemente, reduz a necessidade de intervenção mecânica, disponibilizando a utilização da mão de obra técnica para outras necessidades.

Com o desenvolvimento do dispositivo, atingiu-se o objetivo geral maior, eficiência em um sistema de manutenção autônoma, onde foram minimizadas as perdas produtivas do processo de uma empresa têxtil. 


\section{Referências}

ABIT (São Paulo) (Org.). Quem somos. 2017. Disponível em: <http://www.abit.org.br/cont/quemsomos>. Acesso em: 05 maio 2019.

ABRANCHES, G. P.; SILVA, S. R; CUNHA, V. T. da. Manual da gerência de confecção. Volume 2. Rio de Janeiro: Gráfica do Senai-DN, 1995.

ARAÚJO, M. Tecnologia do vestuário. Lisboa: Fundação Calouste Gulbenkian, 1996.

BOUÇAS, C. Estudo indica as áreas com maior potencial de expansão para têxteis. 2017. Disponível em:

<https://www.valor.com.br/empresas/5153612/abit-estudo-indica-areas-commaior-potencial-de-expansao-para-texteis>. Acesso em: 24 abr. 2018.

COSTA, M. I. Políticas de design para o fomento da inovação na cadeia de valor Têxtil/Confecção de moda de Santa Catarina. 2011. 270 f. Tese (Doutorado em Design). PUC, Rio de Janeiro, 2011. Disponível em: $<$ http://www2.dbd.pucrio.br/pergamum/tesesabertas/0721265_2011_pretextual.pdf>. Acesso em: 11 abr. 2019.

GONSALVES, E. P. Conversas sobre iniciação à pesquisa científica. Campinas, SP: Editora Alínea, 2011.

XENOS, H. G. Gerenciando a Manutenção Produtiva. Belo Horizonte. INDG Tecnologia e Serviços Ltda, 2004.

KAGERMANN, H.; WAHLSTER, W.; HELBIG, J. Das Zukunftsprojekt Industrie 4.0: Handlungsempfehlungen zur Umsetzung. Promotorengruppe Kommunikat. Berlin, p.1-54, 2013.

MELO, M. O. B. C. Inovações Tecnológicas na Cadeia Produtiva Têxtil: Análise e Estudo de Caso em Indústria no Nordeste do Brasil. Revista Produção On Line, Florianópolis, v. 7, p.1-19, 01 ago. 2007.

NELSON, R. R.; WINTER, S. Uma teoria evolucionária da mudança econômica. Campinas, Unicamp, 2005. p. 631.

SCHWAB, K. The Fourth Industrial Revolution. USA: Crown Business, 2017.

SILVEIRA, C. B. O Que é Indústria 4.0 e Como Ela Vai Impactar o Mundo. 2016. Disponível em: <https://www.citisystems.com.br/industria-4-0/\#>. Acesso em: 17 abr. 2018. 